\title{
The Site of Oxygen Delivery Into a Home Ventilator Affects Recorded Volumes
}

\author{
Erwan d'Aranda, Pierre-Julien Cungi, Quentin Mathais, Mickaël Cardinal, Pierre Esnault, \\ Cédric Nguyen, Julien Bordes, Eric Meaudre, and Philippe Goutorbe
}

\begin{abstract}
BACKGROUND: Long-term home mechanical ventilation is increasingly used by patients with chronic respiratory failure. Storage of medical data in the cloud is expanding, and ventilation can be monitored remotely. The aim of this bench study was to determine whether tidal volume $\left(V_{T}\right)$ can be affected by the location of supplemental oxygen placement. METHODS: We tested 4 home ventilators in a bench test using a dual-chamber test lung to test the addition of supplemental oxygen placement via a connector in the circuit (ie, front intake port) versus via the manufacturer's rear intake port, with different oxygen supply flows of $2,4,6$, and $8 \mathrm{~L} / \mathrm{min}$. We compared the effectively delivered $V_{T}$ as measured with a pneumotachograph (ie, measured $V_{T}$ ) versus the $V_{T}$ reported by each home ventilator (ie, monitored $V_{T}$ ). RESULTS: For all of the home ventilators, the monitored $V_{T}$ and measured $V_{T}$ were comparable when the rear oxygen intake was used, regardless of oxygen flow. However, when the front oxygen intake was used, the monitored $V_{T}$ as measured by the ventilators was significantly lower than the measured $\mathrm{V}_{\mathrm{T}}$, with the greatest difference reaching $29 \%$ for the highest oxygen flow tested $(8 \mathrm{~L} / \mathrm{min})$. CONCLUSIONS: The monitored $\mathrm{V}_{\mathrm{T}}$ may be inaccurate if oxygen is added with a connector in the circuit, which may have consequences on both the individual level and collective level (ie, big data analysis). Physicians who analyze data from home ventilators should be aware of the site of oxygen supplementation and promote use of only the rear oxygen intake. Key words: home ventilator; oxygen administration; tidal volume; telemonitoring; cloud; bench test. [Respir Care 2020;65(3):288-292. (C) 2020 Daedalus Enterprises]
\end{abstract}

\section{Introduction}

Long-term home mechanical ventilation is increasingly used by patients with chronic respiratory failure. ${ }^{1}$ In a recent study, Masefield et $\mathrm{al}^{2}$ summarized the prev-

Drs d'Aranda, Cungi, Mathais, Cardinal, Esnault, Meaudre, and Goutorbe are affiliated with the Intensive Care Unit, and Drs Nguyen and Bordes are affiliated with the Anesthesia Department, Sainte Anne Military Teaching Hospital, Toulon, France. Dr Meaudre is also affiliated with the French Military Health Service Academy Unit, Ecole du Valde-Grâce, Paris, France.

The authors have disclosed no conflicts of interest.

Correspondence: Erwan d'Aranda MD, Hôpital d'Instruction des Armées Sainte Anne, Service de Réanimation, BP 600, 83800 Toulon Cedex 9, France. E-mail: erwan.daranda@gmail.com.

DOI: $10.4187 /$ respcare. 06829 alence from several surveys: 12.9 per 100,000 in a Canadian report, ${ }^{3}$ and 9.9 and 12 per 100,000 in Australia and New Zealand, respectively. ${ }^{4}$ The latter study of 2,725 subjects showed that a pressure targeted mode was used in $95.5 \%$ of cases. Home ventilators are pressure ventilators and, in most cases, ${ }^{5}$ use a turbine. The turbine generates flow, which is regulated to maintain the required pressure via feedback from pressure sensor. The volume generated should be monitored because it varies with the patient's breathing patterns (ie, compliance, resistance, and muscle effort).

Patients often benefit from supplemental oxygen to improve gas exchange. Oxygen is often delivered through an orifice on the ventilator or by a T-piece positioned in the patient circuit. The single-limb circuit may be preferred over the dual-limb circuit because it is less cumbersome for the patients, even if the expiratory volume cannot be monitored. A number of home ventilators on the market do not have a rear oxygen port. To our 
knowledge, no one has studied the influence of the site of oxygen supplementation on the monitored tidal volume $\left(\mathrm{V}_{\mathrm{T}}\right)$. Therefore, we analyzed the volume actually delivered to the patient and the volume indicated by the home ventilator by varying the location of oxygen intake and oxygen flow on a test lung.

\section{See the Related Editorial on Page 404}

\section{Methods}

This experimental study was carried out as a bench test as described by Aslanian et al, ${ }^{6}$ consisting of a dual test lung (adult/infant lung simulator, Michigan Instruments, Grand Rapids, Michigan) (Fig. 1). Each tested ventilator was connected by a single-limb circuit with a ventilatorcontrolled exhalation valve (without leaks during inspiration) to the first chamber of the test lung. The 2 chambers were physically connected by a small metal component that allowed the driving chamber to lift the testing chamber. The second chamber (ie, the driving chamber) was pressurized by a ventilator (PB 840, Puritan Bennett, Covidien), which was recognized as an inspiratory effort by the tested ventilator. The drive ventilator was set at a breathing frequency of 15 breaths/min and inspiratoryexpiratory ratio of 1:2. Oxygen supplementation was provided at either the back of the ventilator as recommended by the manufacturer (ie, the rear intake port), or via a T-piece positioned between the ventilator and the patient circuit (ie, the front intake port). The oxygen flow was regulated by a precision flow meter (FlowAnalyser PF300; imtmedical, Buchs, Switzerland). Measured $\mathrm{V}_{\mathrm{T}}$ was determined using a pneumotachograph between the patient circuit and test lung (Fleisch 6V, Lausanne, Switzerland), and was recalibrated between each ventilator tested. Lung resistance was $20 \mathrm{~cm} \mathrm{H}_{2} \mathrm{O} / \mathrm{L} / \mathrm{s}$, and a compliance of $60 \mathrm{~mL} / \mathrm{cm} \mathrm{H}_{2} \mathrm{O}$ was applied to the test lung.

We studied 4 models (different serial numbers) of 4 ventilators: Legendair (Covidien [AIROX], Dublin, Ireland), PB560 (Covidien, Mansfield, Massachusetts), Vivo50 (Breas Medical, Mölnlycke, Sweden), and Trilogy 100 (Philips, Eindhoven, The Netherlands). The ventilator settings were patient-initiated and -terminated breaths with a PEEP of $5 \mathrm{~cm} \mathrm{H}_{2} \mathrm{O}$ and inflating pressure of 10 above PEEP. We studied 4 oxygen supply flows: 2, 4, 6, and $8 \mathrm{~L} / \mathrm{min}$. For each oxygen flow, we noted the $\mathrm{V}_{\mathrm{T}}$ delivered by the home ventilator (ie, monitored $\mathrm{V}_{\mathrm{T}}$ ) and the $\mathrm{V}_{\mathrm{T}}$ effectively received by the patient on the pneumotachograph (ie, measured $\mathrm{V}_{\mathrm{T}}$ ). Oxygen bleed-in was carried out once at the back of the ventilator and once at the front. Each measurement was repeated 5 times (one sequence is one measure for each oxygen flow).

\section{QUICK LOOK}

\section{Current knowledge}

Use of cloud storage for medical data is expanding, and ventilation can be monitored remotely as home ventilator use increases. Supplemental oxygen placement can be delivered via a connector in the circuit or the ventilator's rear intake port. The site of oxygen supplementation can affect delivered tidal volume.

\section{What this paper contributes to our knowledge}

On a home ventilator, when oxygen was added with a connector in the circuit, the monitored tidal volume falsely decreased. Physicians who analyze data from home ventilators should be aware of the site of oxygen supplementation and avoid oxygen bleed-in via the inspiratory limb.

This study was performed at Sainte Anne Military Teaching Hospital, Toulon, France, and the ethics review board of this institution approved the research protocol.

\section{Statistical Analysis}

Quantitative data are given as mean (SD). $\mathrm{V}_{\mathrm{T}}$ and oxygen flow for each oxygen admission were compared with 2-way covariance analysis (ANOVA test). Tests were repeated for each ventilator. $P<.05$ were considered significant. For each home ventilator model, we compared the measured $\mathrm{V}_{\mathrm{T}}$ and the monitored $\mathrm{V}_{\mathrm{T}}$.

\section{Results}

For each ventilator, the mean difference between the volume indicated by the tested home ventilator and the volume received by the test lung (PB560, 5.7\%; Vivo50, 2.7\%; Legendair, $8 \%$; Trilogy, 6.7\%) were lower than the $10 \%$ standard (F1246-91 of the American Society for Testing and Materials; https://www.astm.org/Standards/ F1246.htm, Accessed August 29, 2019).

For all ventilators, the monitored $\mathrm{V}_{\mathrm{T}}$ and measured $\mathrm{V}_{\mathrm{T}}$ were comparable when the rear oxygen intake was used, regardless of oxygen flow. In contrast, the monitored $\mathrm{V}_{\mathrm{T}}$ was significantly lower than the measured $\mathrm{V}_{\mathrm{T}}$ when the front oxygen intake was used. This difference begins with $2 \mathrm{~L} / \mathrm{min}$ and increases to $29 \%$ with increased oxygen flow. Data for the tests with the Vivo50 are presented in Table 1 as an example. To combine all of the measurements, we expressed the results in variations of measured $\mathrm{V}_{\mathrm{T}}$ and monitored $\mathrm{V}_{\mathrm{T}}$. The baseline 


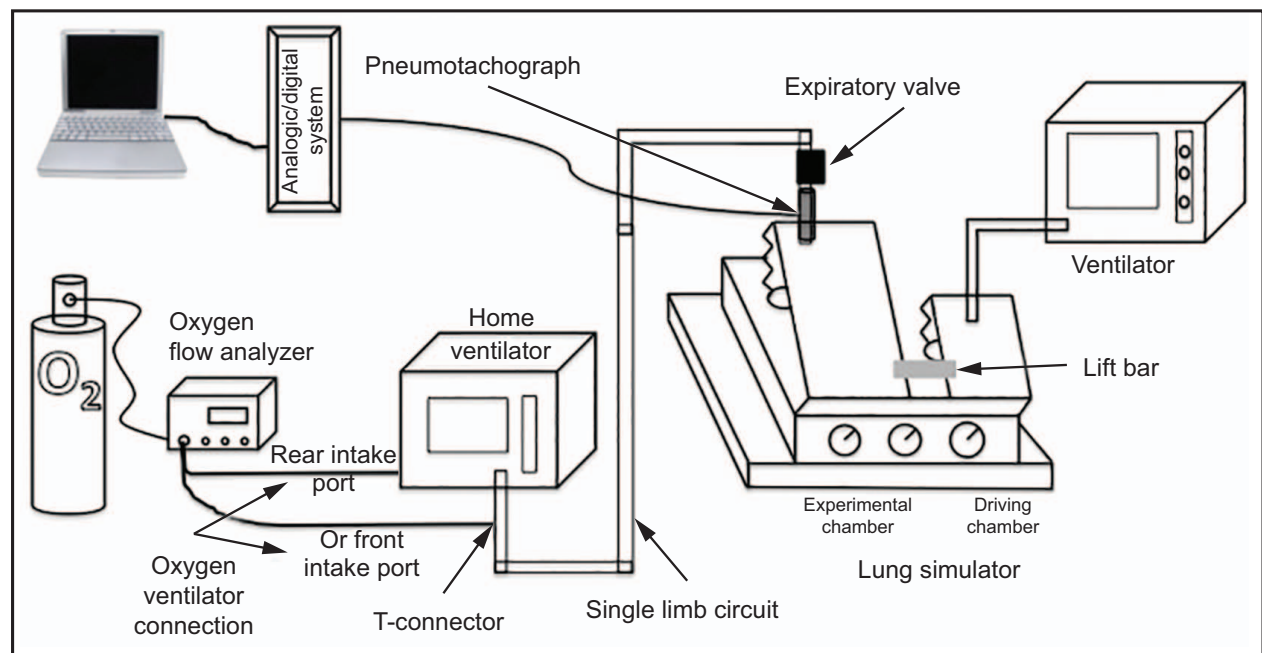

Fig. 1. Experimental setup.

Table 1. Measured $\mathrm{V}_{\mathrm{T}}$ and Monitored $\mathrm{V}_{\mathrm{T}}$ With the Vivo50 Ventilator According to Oxygen Admission Location

\begin{tabular}{lccc}
\hline \hline $\mathrm{O}_{2}$ Flow, L/min & $\begin{array}{c}\text { Measured } \\
\mathrm{V}_{\mathrm{T}}, \mathrm{mL}\end{array}$ & $\begin{array}{c}\text { Monitored } \\
\mathrm{V}_{\mathrm{T}}, \mathrm{mL}\end{array}$ & $P$ \\
\hline Rear intake port & & & .20 \\
2 & $543.3 \pm 39.9$ & $556.9 \pm 30.9$ & \\
4 & $551.7 \pm 40.8$ & $551.7 \pm 32.7$ & \\
6 & $559.2 \pm 39.7$ & $549.1 \pm 33.8$ & \\
8 & $566.0 \pm 40.0$ & $545.4 \pm 35.3$ & \\
Front intake port & & & \\
2 & $546.3 \pm 40.7$ & $522.1 \pm 27.2$ & \\
4 & $554.7 \pm 40.7$ & $481.9 \pm 25.0$ & \\
6 & $564.0 \pm 39.8$ & $436.6 \pm 26.1$ & \\
8 & $571.0 \pm 40.4$ & $401.1 \pm 21.1$ & \\
& & & \\
\hline Data are presented as mean \pm SD. & & \\
$\mathrm{V}_{\mathrm{T}}=$ tidal volume & & \\
\hline
\end{tabular}

(100\%) was measured $\mathrm{V}_{\mathrm{T}}$ with $2 \mathrm{~L} /$ min oxygen flow on the rear intake port (Fig. 2).

\section{Discussion}

This bench study shows that the site of supplemental oxygen intake influences the monitored $\mathrm{V}_{\mathrm{T}}$. When oxygen bleed-in is introduced after the ventilator flow sensor (ie, via the front intake port), the monitored $\mathrm{V}_{\mathrm{T}}$ is minimized although the real $V_{T}$ remains the same. In the case of a higher oxygen flow, this error could reach 29\% (eg, with the Trilogy 100 and the Vivo50 at $8 \mathrm{~L} / \mathrm{min}_{2}$ ). However, we found no difference between the monitored $\mathrm{V}_{\mathrm{T}}$ and measured $\mathrm{V}_{\mathrm{T}}$ when the rear intake was used. These findings may be explained by the intake's position after the ventilator flow sensor, meaning this flow cannot be measured even though the oxygen flow is part of a patient's $\mathrm{V}_{\mathrm{T}}$.

During volume control, the addition of oxygen flow in the inspiratory limb increases the $\mathrm{V}_{\mathrm{T}}$, whereas with pressure control, the inspiratory pressure target is obtained earlier and the ventilator indicates a lower $\mathrm{V}_{\mathrm{T}}$ than the actual $V_{T}$ received by the patient. This study used a single-limb valve circuit, which is currently used for tracheostomized patients. This group represents $\sim 10 \%$ of home mechanical ventilation in a European study. ${ }^{5}$ In this case, the difference between monitored and actual $\mathrm{V}_{\mathrm{T}}$ could prove harmful.

With a single-limb leak circuit for noninvasive ventilation, the difference should be low (ie, the influence of oxygen is reduced by the leakage rate, which can reach $60 \mathrm{~L} / \mathrm{min}$ ). ${ }^{7,8}$ Further, oxygen flow would be reduced secondary to total leak. Ventilators that do not have a rear oxygen intake should not be used in tracheostomized patients, although they could still be used as rescue ventilators. Another bench study has reported that $\mathrm{V}_{\mathrm{T}}$ may be underestimated to varying extents by home ventilators. ${ }^{9}$

Internal memory data from a ventilator can be reviewed by a clinician to assess the efficacy and tolerance of the ventilation. ${ }^{10,11}$ Moreover, the use of telemonitoring patients' home ventilator patterns is growing. ${ }^{12}$ If the physician cannot see the location of the oxygen input, misinterpretation of the monitored $\mathrm{V}_{\mathrm{T}}$ could lead to incorrect pressure increases, leading to overinflation and generating intrinsic PEEP or unloading respiratory muscles. For example, at the individual level, a physician reading a remotely monitored mean $\mathrm{V}_{\mathrm{T}}$ of $400 \mathrm{~mL}$ for a adult male patient ventilated in pressure-support mode could consider increasing the level of the pressure support, which would not be indicated if the actual mean 

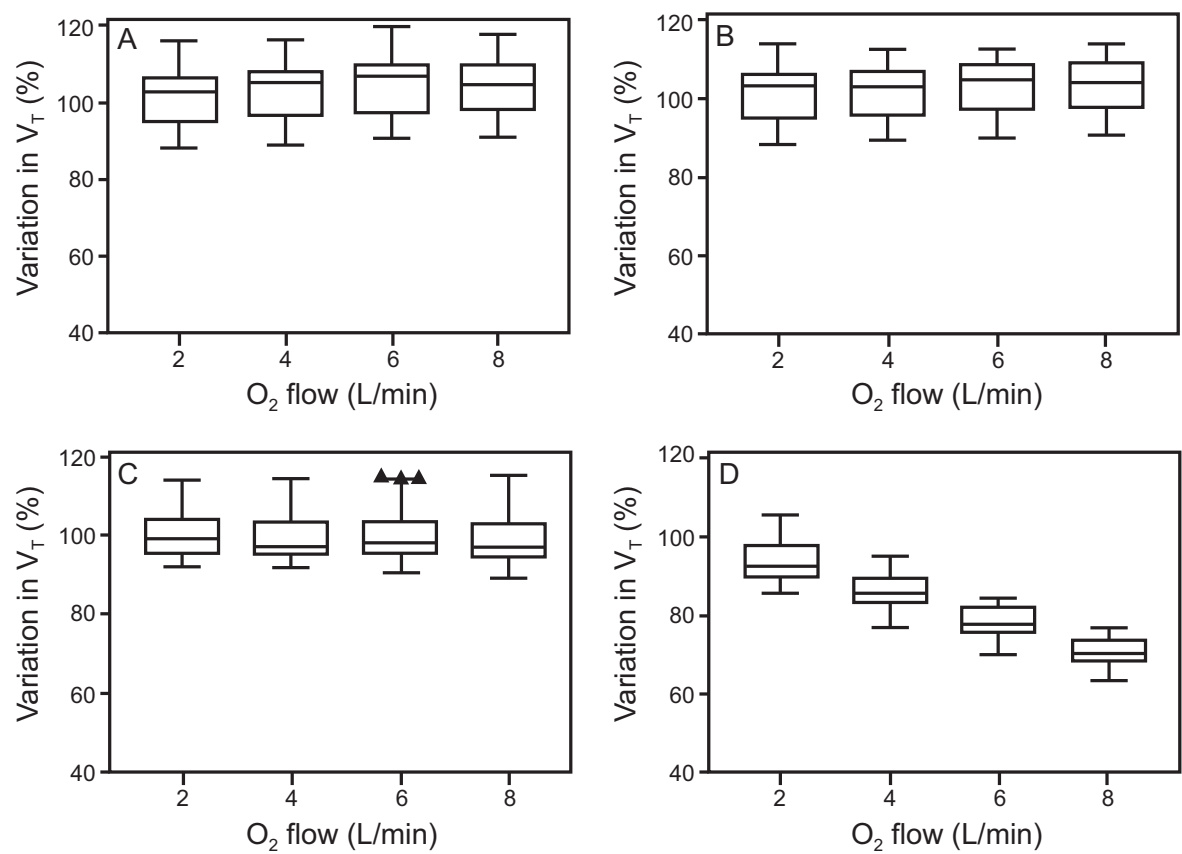

Fig. 2. Variations in measured $(A$ and $C)$ and monitored $(B$ and $D)$ tidal volume $\left(V_{T}\right)$ according to oxygen admission location for all tested home ventilators. $A$ : Measured $V_{T}$, rear intake port, $B$ : monitored $V_{T}$, rear intake port, $C$ : measured $V_{T}$, front intake port, and $\mathrm{D}$ : monitored $\mathrm{V}_{\mathrm{T}}$, front intake port. Triangles indicate height values.

$\mathrm{V}_{\mathrm{T}}$ is $520 \mathrm{~mL}$, a difference that could occur in the worst-case scenario. If the patient experiences air trapping, increasing the pressure level is not the best solution.

At a collective level, results of big data studies would be incorrect. Manufacturers with the main share of the home ventilator market and cloud data management may be able to analyze rapidly a large cohort of tracheostomized receiving volume ventilation. For example, with a breathing frequency of 10 breaths/min, an inspiratoryexpiratory ratio of $1: 2$, and $3 \mathrm{~L} / \mathrm{min} \mathrm{O}_{2}$ for each $\mathrm{V}_{\mathrm{T}}$, $100 \mathrm{~mL}$ is added to the oxygen flow. Is a $100-\mathrm{mL}$ error acceptable for monitoring $\mathrm{V}_{\mathrm{T}}$, especially to determine whether a home ventilator is effective? Exploiting these inexact data through big data may lead to the risk of inexact conclusions for carbon dioxide or a survival end point. The limitations of our study are related to the bench test and extrapolation to patients.

\section{Conclusions}

Physicians who analyze data from home ventilators should promote the use of only the rear oxygen intake. $\mathrm{V}_{\mathrm{T}}$ and minute volume may be underestimated when oxygen is added with a connector in the circuit (ie, the front oxygen intake), which may have damaging consequences at both the individual level and collective level (ie, big data analysis).

\section{REFERENCES}

1. Hind M, Polkey MI, Simonds AK. AJRCCM: 100-year anniversary. homeward bound: a centenary of home mechanical ventilation. Am J Respir Crit Care Med 2017;195(9):1140-1149.

2. Masefield S, Vitacca M, Dreher M, Kampelmacher M, Escarrabill J, Paneroni M, et al. Attitudes and preferences of home mechanical ventilation users from four European countries: an ERS/ELF survey. ERJ Open Res 2017;3(2):2015-2017.

3. Rose L, McKim DA, Katz SL, Leasa D, Nonoyama M, Pedersen C, et al. Home mechanical ventilation in Canada: a national survey. Respir Care 2015;60(5):695-704.

4. Garner DJ, Berlowitz DJ, Douglas J, Harkness N, Howard M, McArdle $\mathrm{N}$, et al. Home mechanical ventilation in Australia and New Zealand. Eur Resp J 2013;41(1):39-45.

5. Lloyd-Owen SJ, Donaldson GC, Ambrosino N, Escarabill J, Farre R, Fauroux B, Robert D, et al. Patterns of home mechanical ventilation use in Europe: results from the Eurovent survey. Eur Respir J 2005; 25(6):1025-1031.

6. Aslanian P, El Atrous S, Isabey D, Valente E, Corsi D, Harf A, et al. Effects of flow triggering on breathing effort during partial ventilatory support. Am J Respir Crit Care Med 1998;157(1):135-143.

7. Goutorbe P, d'Aranda E, Asencio Y, Esnault P, Prunet B, Bordes J, et al. Leaks can dramatically decrease $\mathrm{FiO} 2$ on home ventilators: a bench study. BMC Res Notes 2013;6:282.

8. Borel JC, Sabil A, Janssens J-P, Couteau M, Boulon L, Lévy P, et al. Intentional leaks in industrial masks have a significant impact on efficacy of bilevel noninvasive ventilation: a bench test study. Chest 2009;135(3):669-677.

9. Lujan M, Sogo A, Pomares X, Monso E, Sales B, Blanch L. Effect of leak and breathing pattern on the accuracy of tidal volume estimation by commercial home ventilators: a bench study. Respir Care 2013;58(5):770-777. 
Oxygen Delivery Placement in Home Mechanical Ventilators

10. Arnal J-M, Texereau J, Garnero A. Practical insight to monitor home NIV in COPD patients. COPD 2017;14(4):401-410.

11. Mansell SK, Cutts S, Hackney I, Wood MJ, Hawksworth K, Creer $\mathrm{DD}$, et al. Using domiciliary non-invasive ventilator data downloads to inform clinical decision-making to optimise ventilation delivery and patient compliance. BMJ Open Respir Res 2018; 5(1):e000238.

12. Ambrosino N, Vitacca M, Dreher M, Isetta V, Montserrat JM, Tonia T, et al. Tele-monitoring of ventilator-dependent patients: a European Respiratory Society statement. Eur Respir J 2016;48(3):648-663.

This article is approved for Continuing Respiratory Care Education credit. For information and to obtain your CRCE

(free to AARC members) visit 